\title{
Global Gene Expression Profiling in PPAR- $y$ Agonist-Treated Kidneys in an Orthologous Rat Model of Human Autosomal Recessive Polycystic Kidney Disease
}

\author{
Daisuke Yoshihara, ${ }^{1,2}$ Masanori Kugita, ${ }^{1}$ Tamio Yamaguchi, ${ }^{1,3}$ Harold M. Aukema, ${ }^{3}$ \\ Hiroki Kurahashi, ${ }^{2}$ Miwa Morita, ${ }^{1}$ Yoshiyuki Hiki, ${ }^{4}$ James P. Calvet, ${ }^{5}$ Darren P. Wallace, ${ }^{5}$ \\ Takafumi Toyohara, ${ }^{6}$ Takaaki Abe, ${ }^{6}$ and Shizuko Nagao ${ }^{1}$ \\ ${ }^{1}$ Education and Research Center of Animal Models for Human Diseases, Fujita Health University, Toyoake, Aichi 4701192, Japan \\ ${ }^{2}$ Division of Molecular Genetics, Institute for Comprehensive Medical Science, Fujita Health University, Toyoake, Aichi 4701192, Japan \\ ${ }^{3}$ Department of Human Nutritional Sciences, University of Manitoba, Winnipeg, MB, Canada R3T 2N2 \\ ${ }^{4}$ School of Health Sciences, Fujita Health University, Toyoake, Aichi 4701192, Japan \\ ${ }^{5}$ The Kidney Institute, University of Kansas Medical Center, Kansas City, KS 66160, USA \\ ${ }^{6}$ Department of Clinical Biology and Hormonal Regulation, Tohoku University Graduate School of Biomedical Engineering, \\ Sendai, Miyagi 9808574, Japan
}

Correspondence should be addressed to Shizuko Nagao, shizun@fujita-hu.ac.jp

Received 18 January 2012; Accepted 17 February 2012

Academic Editor: Yuji Kamijo

Copyright (C) 2012 Daisuke Yoshihara et al. This is an open access article distributed under the Creative Commons Attribution License, which permits unrestricted use, distribution, and reproduction in any medium, provided the original work is properly cited.

\begin{abstract}
Kidneys are enlarged by aberrant proliferation of tubule epithelial cells leading to the formation of numerous cysts, nephron loss, and interstitial fibrosis in polycystic kidney disease (PKD). Pioglitazone (PIO), a PPAR- $\gamma$ agonist, decreased cell proliferation, interstitial fibrosis, and inflammation, and ameliorated PKD progression in PCK rats (Am. J. Physiol.-Renal, 2011). To explore genetic mechanisms involved, changes in global gene expression were analyzed. By Gene Set Enrichment Analysis of 30655 genes, 13 of the top 20 downregulated gene ontology biological process gene sets and six of the top 20 curated gene set canonical pathways identified to be downregulated by PIOtreatment were related to cell cycle and proliferation, including EGF, PDGF and JNK pathways. Their relevant pathways were identified using the Kyoto Encyclopedia of Gene and Genomes database. Stearoylcoenzyme A desaturase 1 is a key enzyme in fatty acid metabolism found in the top 5 genes downregulated by PIO treatment. Immunohistochemical analysis revealed that the gene product of this enzyme was highly expressed in PCK kidneys and decreased by PIO. These data show that PIO alters the expression of genes involved in cell cycle progression, cell proliferation, and fatty acid metabolism.
\end{abstract}

\section{Introduction}

Polycystic kidney diseases (PKD) are characterized by progressive enlargement of numerous fluid-filled cysts in both kidneys, often leading to chronic kidney disease (CKD). Autosomal dominant PKD (ADPKD) is one of the most common hereditary disorders in humans with an incidence of $1: 500-1,000$, caused by mutations in the PKD1 or PKD2 gene. Progressive kidney enlargement is due to aberrant proliferation of the cystic epithelia, together with an accumulation of fluid into the cyst cavities due to transepithelial chloride $\left(\mathrm{Cl}^{-}\right)$and fluid secretion [1-3]. Autosomal recessive PKD (ARPKD) is known as a juveniletype cystic disease with an incidence of $1: 20,000$ [3]. Kidneys in ARPKD patients are characterized by cystic fusiform dilations of the collecting ducts accompanied by increased cell proliferation and fluid secretion, leading to massive kidney enlargement and renal failure occurring in the first few years after birth [4]. Increased cell proliferation, stimulated fluid secretion, and interstitial fibrosis are often observed in cystic liver disease in ARPKD as well [5]. 
Peroxisome proliferator-activated receptors (PPARs) belong to a nuclear receptor superfamily of ligand-activated transcription factors with subtypes $\alpha, \beta / \delta$, and $\gamma$. PPAR- $\gamma$ is widely expressed in several organs including kidneys and known to be activated by fatty acids $[6,7]$. Antidiabetic agents, pioglitazone (PIO), troglitazone, ciglitazone, and rosiglitazone, are used to control blood sugar levels in patients with diabetes mellitus. These PPAR- $\gamma$ agonists also have important roles in regulation of cell cycle, inhibition of fibrosis, infiltration and metastasis of cancer cells, and modulation of inflammatory cytokines.

Treatment with PIO improved survival and ameliorated cardiac defects and the degree of renal cystogenesis in embryos of $P k d 1^{-/-}$mice in a previous study [8]. In addition, long-term treatment of this agonist improved endothelial function by increasing production of nitric oxide in adult heterozygous $\mathrm{Pkd1}^{+/-}$mice [8]. Another PPAR- $\gamma$ agonist, rosiglitazone attenuated PKD progression and prolonged survival of Han: SPRD Cy rats [9]. In our recent study, daily treatment of PIO ameliorated polycystic kidney disease through inhibiting Raf/MEK/ERK and AKT/mTOR/S6 signaling cascades in the PCK rat, an orthologous model of human ARPKD [10]. These findings suggest that PPAR- $\gamma$ agonists may have therapeutic value in ARPKD via altering several cellular signaling pathways. In the current study, we applied global gene expression profiling to explore novel cellular signaling pathways potentially related to the ameliorating effects of PIO in PCK rat kidneys.

\section{Methods}

2.1. PCK Rat and Study Design. PCK rats were originally derived from a strain of Sprague-Dawley rats in Japan and descendants of this colony have been maintained at the Education and Research Center of Animal Models for Human Diseases, Fujita Health University. PCK rats and normal Sprague Dawley rats (+/+; Charles River Japan Inc., Kanagawa, Japan) were allowed free access to water and food throughout the study. Female PCK and $+/+$ rats, aged 4-20 weeks ( $n=10$ per gender) were randomly assigned to one of two groups: treatment with $10 \mathrm{mg} / \mathrm{kg}$ PIO (Takeda Pharmaceutical Company Limited, Osaka, Japan) or vehicle control $(0.5 \%$ DMSO) by gavage every day as previously reported [10]. The protocol for the ethics and use of these animals was approved by the Animal Care and Use Committee at Fujita Health University.

At 20 weeks of age, rats were anesthetized with sodium pentobarbital (Schering-Plough Corp., Kenilworth, NJ), and the kidneys were removed rapidly, causing lethal exsanguination. Half of the left kidney was frozen in liquid nitrogen for RNA extraction. Half of the right kidney was immersed in $4 \%$ paraformaldehyde, embedded in paraffin, and sectioned for immunohistochemistry.

2.2. RNA Extraction. RNA was extracted from kidneys of rats with or without PIO treatment using a monophasic solution of phenol/guanidine isothiocyanate and TRIzol reagent (Invitrogen Co., Carlsbad, CA, USA) in accordance with their manual, and the samples were incubated with
RNase-free DNase I (Ambion, TX, USA). The quality and concentration of each sample was confirmed by spectrophotometry (NanoDrop ND-1000; Asahi glass Co. Ltd., Tokyo, Japan). Total RNA obtained from three females was pooled in each PIO-treated or control vehicle-treated (CONT) group in accordance with our previous report [11].

2.3. Microarrays. DNA microarray experiments were performed essentially as described previously [11]. Briefly, $500 \mathrm{ng}$ aliquots of total RNA obtained from kidneys of five rats were labeled using a Quick Amp Labeling Kit, one-color (Agilent Technologies, Inc., Santa Clara, CA, USA), according to the manufacturer's instructions. The pooled renal RNA of PIO- or vehicle-treated PCK rats were labeled with the $\mathrm{Cy} 3$-fluorescence dye. After determination of labeling efficiency, $1.65 \mu \mathrm{g}$ aliquots of Cy3-labeled RNA were hybridized using the Gene Expression hybridization kit (Agilent Technologies) onto Rat Oligo Microarrays (Agilent Technologies, product no. G4130A) according to the manufacturer's hybridization protocol. The microarray slides were examined with an Agilent microarray scanner and software. Data analysis was performed with Agilent Feature Extraction software (version A.7.1.1).

Data from microarray experiments of PIO- or vehicletreated rats were analyzed independently. Primary microarray data are available from the Gene Expression Omnibus (GEO) (accession number GSE00000). Evaluation of signal intensity was divided into three classes, $\{0\}$ : nondetected, $\{1\}$ : weakly detected, and $\{2\}$ : strongly detected transcription product. Gene ontology analysis of biological process (C5BP) and curated gene sets of canonical pathways (C2CP) were analyzed by importing the data into Gene Set Enrichment Analysis (GSEA version 2, the Broad Institute/Massachusetts Institute of technology, USA) [12].

Using the GeneSpring software, the changed probes were listed as "Log 2 ratio was over 1 (over 2 -fold) or less than -1 (less than 1/2-fold) between PIO group and CONT group" and "the signal evaluation was $\{2\}$ (strongly detected) in both groups". In the changed genes, Kyoto Encyclopedia of Gene and Genomes (KEGG) analysis was used [13].

\subsection{Real-Time Reverse Transcriptase Polymerase Chain Reac-} tion (RT-PCR). cDNA was produced from total RNA by reverse transcriptase using random hexamer primers (SuperScript II First Strand Synthesis System; Invitrogen Co., Carlsbad, CA, USA). To compare gene expression patterns of PCK kidneys with PIO or vehicle treatment, we selected a key enzyme in fatty acid metabolism, stearoyl-coenzyme A desaturase 1 ( $S c d 1)$, and uncoupling protein 1 (Ucp1). Gene expression was detected by real-time RT-PCR (ABI 7300 real-time PCR system; Applied Biosystems, Foster City, CA, USA) using the TaqMan reagent-based chemistry protocol. Glyceraldehyde-3phosphate dehydrogenase (GAPDH) as a housekeeping gene was used for data normalization. The probes of Scd1, UCP-1, and GAPDH were CCCACATGCTCCAAGAGATCTCCAG, CTCTTCAGGGAGAGAAACGCCTGCC, and AACCCATCACCATCTTCCAGGAGCG, respectively (TaqMan Gene 
TABle 1: (a) Top 20 downregulated gene ontology biological process gene sets in PIO-treated compared with vehicle-treated kidneys. The name of biological process is listed in order of nominal $P$ value. (b) Upregulated gene ontology biological process gene sets in PIO-treated compared with vehicle-treated kidneys. The name of biological process is listed in order of nominal $P$ value.

(a)

\begin{tabular}{|c|c|c|}
\hline Name of biological process gene sets & Number of genes in the gene set & Nominal $P$ value \\
\hline Defense response & 98 & 0.000 \\
\hline Regulation of cell proliferation & 136 & 0.000 \\
\hline Cell cycle phase & 53 & 0.000 \\
\hline Positive regulation of cell proliferation & 64 & 0.000 \\
\hline Cell cycle process & 61 & 0.000 \\
\hline Positive regulation of cellular process & 258 & 0.000 \\
\hline Cellular morphogenesis during differentiation & 22 & 0.001 \\
\hline Positive regulation of developmental process & 91 & 0.001 \\
\hline Immune system process & 128 & 0.001 \\
\hline Cellular defense response & 19 & 0.003 \\
\hline Neuron differentiation & 35 & 0.004 \\
\hline Negative regulation of cell proliferation & 73 & 0.004 \\
\hline Neurite development & 27 & 0.005 \\
\hline G Protein signaling coupled to ip 3 second messenger phospholipase $\mathrm{C}$ activating & 22 & 0.005 \\
\hline Inflammatory response & 56 & 0.005 \\
\hline Regulation of response to stimulus & 15 & 0.006 \\
\hline Neuron development & 30 & 0.007 \\
\hline M phase & 27 & 0.007 \\
\hline Interphase & 29 & 0.008 \\
\hline Axonogenesis & 21 & 0.009 \\
\hline
\end{tabular}

(b)

\begin{tabular}{lcc}
\hline Name of biological process gene sets & Number of genes in the gene set & Nominal $P$ value \\
\hline Nitrogen compound catabolic process & 17 & 0.000 \\
Amine catabolic process & 15 & 0.000 \\
Amino acid metabolic process & 46 & 0.000 \\
Amino acid and derivative metabolic process & 58 & 0.000 \\
Organic acid metabolic process & 106 & 0.000 \\
Carboxylic acid metabolic process & 104 & 0.022 \\
\hline
\end{tabular}

Expression Assays; Applied Biosystems). Relative quantification of gene expression was compared to one in SD control vehicle-treated (CONT) kidneys (set to 1.0).

2.5. Immunohistochemistry. Kidney sections were fixed, embedded, and sectioned for immunoreaction as described previously $[10,11]$. Sections were incubated with $S c d 1$ antibody (1:250 ab19862 Abcam, Cambridge, UK) in PBS containing $1 \%$ BSA plus $0.05 \% \mathrm{NaN}_{3}$ overnight at $4^{\circ} \mathrm{C}$. To test for a specific $S c d 1$ immunoreaction in the kidney, mouse IgG2b, $\kappa$ isotype control antibody ( 1 : 200400323 BioLegend, San Diego, CA), was used. Sections were incubated with secondary antibody Histofine MAX-PO (MULTI: for antimouse/rabbit IgG, IgA, and IgM) obtained from Nichirei Biosciences (Tokyo, Japan). Immune reaction products were developed using 3,3'-diaminobenzidine (ENVISION kit HRP Dako Cytomation K3466, Dako Japan Inc., Tokyo, Japan).
2.6. Statistical Analysis. Results are expressed as the arithmetic mean \pm standard error. Statistical comparisons between groups were performed by Student's $t$-test and twoway analysis of variance, and differences were considered to be significant at $P<0.05$.

\section{Results}

3.1. Identification of Differentially Expressed Genes by Expression Profiling. Previous report indicates that PPAR- $\gamma$ agonistic action decreases expression of endothelin receptor type A (EDNRA) [14], suggesting that EDNRA is one of the down-stream target gene of PPAR- $\gamma$ agonists. In our current study, expression of Ednra was also downregulated in PIOtreated kidneys (Log2 ratio $=-1.30)$. EDNRA expression is increased in human ADPKD, and overexpression of Ednra causes cyst formation in transgenic mouse kidneys [15]. Because not only EDNRA but also various genes 
TABle 2: (a) Downregulated gene ontology biological process gene sets from genes with greater than 1.25-fold changes in PIO-treated compared with vehicle-treated kidneys. The name of biological process is listed in order of nominal $P$ value. (b) Common genes found in cell cycle or cell proliferation gene sets downregulated by PIO treatment. $\checkmark$ : listed gene in the gene set, —: non-listed gene in the gene set. (c) Upregulated gene ontology biological process gene sets with greater than 1.25 -fold changes in PIO-treatmed compared with vehicle-treated kidneys.

(a)

\begin{tabular}{lcc}
\hline Name of biological process gene sets & Number of genes in the gene set & Nominal $P$ value \\
\hline Carbohydrate METABOLIC PROCESS & 16 & 0.019 \\
Cell proliferation GO 0008283 & 70 & 0.024 \\
Organelle organization and biogenesis & 34 & 0.025 \\
Cell cycle GO 0007049 & 44 & 0.027 \\
Negative regulation of cell proliferation & 28 & 0.032 \\
Cell cycle process & 31 & 0.037 \\
\hline
\end{tabular}

(b)

\begin{tabular}{|c|c|c|c|c|c|}
\hline \multirow[b]{2}{*}{ Gene symbol } & \multirow[b]{2}{*}{ Description } & \multicolumn{4}{|c|}{ Name of biological process gene sets } \\
\hline & & Cell cycle GO 0007049 & $\begin{array}{c}\text { Negative } \\
\text { regulation of } \\
\text { cell proliferation }\end{array}$ & Cell cycle process & $\begin{array}{c}\text { Cell } \\
\text { proliferation } \\
\text { GO 0008283 }\end{array}$ \\
\hline $\mathrm{Brca} 2$ & Breast cancer 2 & $\checkmark$ & $\checkmark$ & $\checkmark$ & $\checkmark$ \\
\hline$C d k n 2 b$ & $\begin{array}{l}\text { Cyclin-dependent } \\
\text { kinase inhibitor 2B } \\
\text { (p15, inhibits CDK4) }\end{array}$ & $\checkmark$ & $\checkmark$ & $\checkmark$ & $\checkmark$ \\
\hline Chek1 & $\begin{array}{l}\text { CHK1 checkpoint } \\
\text { homolog }\end{array}$ & $\checkmark$ & $\checkmark$ & $\checkmark$ & - \\
\hline$B U B 1 B$ & $\begin{array}{l}\text { Cell cycle checkpoint } \\
\text { protein kinase Bub1 } \\
\text { Fragment }\end{array}$ & $\checkmark$ & $\checkmark$ & - & $\checkmark$ \\
\hline PLK1 & Pololike kinase 1 & $\checkmark$ & $\checkmark$ & - & $\checkmark$ \\
\hline$C d k n 1 c$ & $\begin{array}{l}\text { Cyclin-dependent } \\
\text { kinase inhibitor 1C }\end{array}$ & $\checkmark$ & $\checkmark$ & $\checkmark$ & - \\
\hline Cul5 & Cullin 5 & $\checkmark$ & $\checkmark$ & $\checkmark$ & $\checkmark$ \\
\hline $\operatorname{Tg} f b 2$ & $\begin{array}{l}\text { Transforming growth } \\
\text { factor, beta } 2\end{array}$ & $\checkmark$ & - & $\checkmark$ & $\checkmark$ \\
\hline Bcat1 & $\begin{array}{l}\text { Branched chain } \\
\text { aminotransferase } 1\end{array}$ & $\checkmark$ & $\checkmark$ & - & $\checkmark$ \\
\hline PTPRC & $\begin{array}{l}\text { Protein tyrosine } \\
\text { phosphatase, receptor } \\
\text { type, C }\end{array}$ & $\checkmark$ & $\checkmark$ & - & $\checkmark$ \\
\hline POLA1 & $\begin{array}{l}\text { Polymerase (DNA } \\
\text { directed), alpha } 1\end{array}$ & $\checkmark$ & $\checkmark$ & - & $\checkmark$ \\
\hline
\end{tabular}

(c)

Name of biological process gene sets

Number of genes in the gene set

Nominal $P$ value

Neurological System Process

40 0.032

may be influenced by PPAR- $\gamma$ agonistic actions, it became intriguing to determine the expression of other potential gene targets of PIO in PCK rat kidneys. 30,655 of 43,379 probes yielded detectable signals in both PIO- and vehicletreated kidneys of PCK rats. The 11,809 genes represented by these 30,655 probes were analyzed by GSEA. In gene ontology analysis of biological process (C5BP) gene sets, 334 were formed from these 11,809 genes. 293 of those 334 gene sets were downregulated in PIO-treated kidneys compared with vehicle-treated kidneys, of which 77 were significantly different $(P<0.05$, Table $1(\mathrm{a}))$. In the top 20 downregulated C5BP gene sets with the greatest significant differences, 13 were related to cell proliferation, cell cycle, morphogenesis, differentiation, and development, and 4 gene sets were related to cellular defense and inflammation. On the other hand, 41 of the 334 gene sets were upregulated in PIO-treated 
kidneys compared with vehicle-treated kidneys, of which 6 were significantly different $(P<0.05$, Table $1(\mathrm{~b}))$. These gene sets were related to catabolic and metabolic processes.

To examine the gene sets with the greatest changes, only 2,611 genes, which changed more than 1.25 -fold in PIO-treated kidneys compared to vehicle-treated kidneys, were analyzed. 141 gene sets were formed from these 2,611 genes. 112 of those 141 gene sets were downregulated in PIO-treated kidneys compared with vehicle-treated kidneys of PCK rats. Of these, 6 gene sets were significantly different $(P<0.05$, Table $2(\mathrm{a})) .4$ of these 6 gene sets are related to cell cycle and cell proliferation (Table $2(\mathrm{a}))$. Common genes in these gene sets include G1/S or G2/M checkpoint related genes, breast cancer 2 (Brca2), cyclin-dependent kinase inhibitor 2B (Cdkn2b), CHK1 checkpoint homolog (Chek1), cell cycle checkpoint protein kinase Bub1 fragment $(B U B 1 B)$, pololike kinase 1 (PLK1), and cyclin-dependent kinase inhibitor 1C (Cdkn1c) (Table 2(b)). Of the remaining 29 of the 141 gene sets that were upregulated in PIO-treated kidneys compared with vehicle-treated kidneys, only one, related to neurological system processes, was significantly elevated $(P<0.05)$ (Table $2(\mathrm{c}))$.

In curated gene sets of canonical pathways (C2CP), 257 were formed from the 11,809 genes detected. 201 of these 257 gene sets were downregulated in PIO-treated kidneys compared with vehicle-treated kidneys, of which 33 were significantly lower $(P<0.05)$. From the 20 downregulated C2CP gene sets with the highest significant differences (lowest $P$ values), 6 gene sets were related to cell cycle and cell proliferation including c-Jun $\mathrm{N}$-terminal kinase $(J N K)$, epidermal growth factor $(E G F)$, and platelet-derived growth factor (PDGF) pathways, and 3 gene sets were related to inflammatory signals including interleukin-1 receptor (IL1R) and interleukin-6 (IL6) pathways (Table 3(a)). One gene set, extracellular matrix (ECM) receptor interaction, also was in the top 20 downregulated in C2CP. On the other hand, 56 of 257 gene sets were upregulated in PIO-treated kidneys compared with vehicle-treated kidneys, of which 5 gene sets were significantly higher $(P<0.05$, Table 3(b)). 3 of these 5 gene sets are related to glutamate, alanine, and aspartate metabolism.

GSEA is a computational method that determines whether an a priori defined set of genes shows statistically significant and concordant differences between two biological states and can detect important biological processes or canonical pathways by using the list rank information without using a threshold [12]. Among the 43,379 probes spotted on the microarray slide, 189 probes were significantly changed. From these 189 probes, 31 genes were identified by KEGG analysis. 23 of those 31 genes were downregulated in PIO-treated compared with vehicle-treated kidneys (Table 4(a)). Two key enzymes in fatty acid metabolism, stearoyl-coenzyme A desaturase $1(S c d 1)$ and uncoupling protein 1 (Ucp1), which are involved in PPAR signaling were in the top 15 genes downregulated by PIO treatment. On the other hand, 8 of the 31 genes were upregulated in PIO-treated kidneys compared with vehicle-treated kidneys (Table 4(b)).
TABLE 3: (a) Top 20 downregulated curated gene sets of canonical pathways in PIO-treated compared with vehicle-treated kidneys. The name of biological process is listed in order of nominal $P$ value. (b) Upregulated curated gene sets of canonical pathways in PIO-treated compared with vehicle-treated kidneys. The name of biological process is listed in order of nominal $P$ value.

(a)

\begin{tabular}{|c|c|c|}
\hline Name of biological process gene sets & $\begin{array}{l}\text { Number of } \\
\text { genes in } \\
\text { the gene } \\
\text { set }\end{array}$ & $\begin{array}{l}\text { Nominal } \\
P \text { value }\end{array}$ \\
\hline HSA04640 hematopoietic cell lineage & 32 & 0.000 \\
\hline $\begin{array}{l}\text { HSA04610 complement and coagulation } \\
\text { cascades }\end{array}$ & 37 & 0.000 \\
\hline HSA04510 focal adhesion & 110 & 0.001 \\
\hline Breast cancer estrogen signaling & 60 & 0.001 \\
\hline $\begin{array}{l}\text { HSA04060 cytokine cytokine receptor } \\
\text { interaction }\end{array}$ & 99 & 0.002 \\
\hline HSA04912 GNRH Signaling Pathway & 64 & 0.002 \\
\hline HSA04110 cell cycle & 44 & 0.003 \\
\hline HSA01430 cell communication & 39 & 0.004 \\
\hline IL1R pathway & 15 & 0.007 \\
\hline Eicosanoid synthesis & 15 & 0.009 \\
\hline HSA04512 ECM receptor interaction & 41 & 0.009 \\
\hline Cell cycle KEGG & 34 & 0.012 \\
\hline ST JNK MAPK pathway & 17 & 0.017 \\
\hline EGF pathway & 23 & 0.023 \\
\hline PDGF pathway & 23 & 0.028 \\
\hline FCER1 pathway & 26 & 0.029 \\
\hline GSK3 pathway & 18 & 0.029 \\
\hline $\begin{array}{l}\text { Prostaglandin and leukotriene } \\
\text { metabolism }\end{array}$ & 19 & 0.032 \\
\hline IL6 pathway & 17 & 0.032 \\
\hline HSA02010 ABC transporters general & 21 & 0.033 \\
\hline
\end{tabular}

(b)

\begin{tabular}{lcc}
\hline Name of biological process gene sets & $\begin{array}{c}\text { Number of } \\
\text { genes in } \\
\text { the gene } \\
\text { set }\end{array}$ & $\begin{array}{c}\text { Nominal } \\
P \text { value }\end{array}$ \\
\hline $\begin{array}{l}\text { HSA00190 oxidative phosphorylation } \\
\text { Glutamate metabolism }\end{array}$ & 37 & 0.000 \\
HSA00252 alanine and aspartate & 15 & 0.000 \\
metabolism & 17 & 0.010 \\
HSA00710 carbon fixation & 15 & 0.019 \\
HSA00251 glutamate metabolism & 17 & 0.019 \\
\hline
\end{tabular}

3.2. Cellular Expression and Distribution of Scd1 in Rodent Polycystic Kidneys. For Scd1 and Ucp1, in order to confirm the mRNA expression by DNA microarray screening above, real-time RT-PCR analysis was performed. The mRNA level of $S c d 1$ in the kidney was increased in PCK rats compared 
TABle 4: (a) Downregulated genes in PIO-treated compared with vehicle-treated (CONT) kidneys of PCK rats. The name of gene symbol was listed in order of PIO/CONT Log2 ratio. (b) Upregulated genes in PIO-treated compared with vehicle-treated (CONT) kidneys of PCK rats. The name of gene symbol was listed in order of PIO/CONT Log2 ratio.

(a)

\begin{tabular}{|c|c|c|c|}
\hline Gene symbol & Description & KEGG pathway & $\mathrm{PIO} / \mathrm{CONT} \log 2$ ratio \\
\hline Olr1436 & Olfactory receptor 1436 & Olfactory transduction & -3.27 \\
\hline Xylt1 & Xylosyltransferase 1 & $\begin{array}{l}\text { Glycosaminoglycan biosynthesis-chondroitin } \\
\text { sulfate/glycosaminoglycan biosynthesis-heparan } \\
\text { sulfate/metabolic pathways }\end{array}$ & -3.03 \\
\hline Map3k10 & Mixed-lineage kinase 2 & MAPK signaling pathway & -2.24 \\
\hline Icoslg & - & $\begin{array}{l}\text { Cell adhesion molecules (CAMs)/intestinal immune } \\
\text { network for IgA production }\end{array}$ & -2.15 \\
\hline Scd1 & Stearoyl-coenzyme A desaturase 1 & $\begin{array}{l}\text { Biosynthesis of unsaturated fatty acids/PPAR } \\
\text { signaling pathway }\end{array}$ & -2.01 \\
\hline Ucp1 & Uncoupling protein 1 & PPAR signaling pathway/Huntington's disease & -1.91 \\
\hline Oxt & Oxytocin, prepropeptide & Neuroactive ligand-receptor interaction & -1.81 \\
\hline Chrm1 & Cholinergic receptor, muscarinic 1 & $\begin{array}{l}\text { Calcium signaling pathway/Neuroactive } \\
\text { ligand-receptor interaction/regulation of actin } \\
\text { cytoskeleton }\end{array}$ & -1.75 \\
\hline$A v p$ & Arginine vasopressin & $\begin{array}{l}\text { Neuroactive ligand-receptor interaction/vascular } \\
\text { smooth muscle contraction/vasopressin-regulated } \\
\text { water reabsorption }\end{array}$ & -1.58 \\
\hline Lpcat2 & $\begin{array}{l}\text { Lysophosphatidylcholine } \\
\text { acyltransferase } 2\end{array}$ & $\begin{array}{l}\text { Glycerophospholipid metabolism/ether lipid } \\
\text { metabolism/metabolic pathways }\end{array}$ & -1.37 \\
\hline Il12rb1 & Interleukin 12 receptor, beta 1 & $\begin{array}{l}\text { Cytokine-cytokine receptor interaction/jak-STAT } \\
\text { signaling pathway }\end{array}$ & -1.34 \\
\hline EDNRA & Endothelin receptor type A & $\begin{array}{l}\text { Calcium signaling pathway/neuroactive } \\
\text { ligand-receptor interaction/vascular smooth muscle } \\
\text { contraction }\end{array}$ & -1.30 \\
\hline$C f d$ & Complement factor D (adipsin) & Complement and coagulation cascades & -1.20 \\
\hline Serpinb5 & $\begin{array}{l}\text { Serine (or cysteine) peptidase } \\
\text { inhibitor, clade B, member } 5\end{array}$ & p53 signaling pathway & -1.19 \\
\hline$H \operatorname{tr} 2 b$ & $\begin{array}{l}\text { 5-Hydroxytryptamine (serotonin) } \\
\text { receptor } 2 \mathrm{~B}\end{array}$ & $\begin{array}{l}\text { Calcium signaling pathway/neuroactive } \\
\text { ligand-receptor interaction/gap junction }\end{array}$ & -1.19 \\
\hline Cox $8 b$ & $\begin{array}{l}\text { Cytochrome c oxidase, subunit } \\
\text { VIIIb }\end{array}$ & $\begin{array}{l}\text { Oxidative phosphorylation/metabolic } \\
\text { pathways/cardiac muscle contraction/Alzheimer's } \\
\text { disease/Parkinson's disease/Huntington's disease }\end{array}$ & -1.17 \\
\hline Peg12 & Paternally expressed 12 & Wnt signaling pathway & -1.11 \\
\hline Sema3d & $\begin{array}{l}\text { Sema domain, immunoglobulin } \\
\text { domain (Ig), short basic domain, } \\
\text { secreted, (semaphorin) 3D }\end{array}$ & Axon guidance & -1.07 \\
\hline Atpla2 & $\begin{array}{l}\text { ATPase, } \mathrm{Na}+/ \mathrm{K}+\text { transporting, } \\
\text { alpha } 2 \text { polypeptide }\end{array}$ & $\begin{array}{l}\text { Cardiac muscle contraction/aldosterone-regulated } \\
\text { sodium reabsorption/proximal tubule bicarbonate } \\
\text { reclamation/salivary secretion/gastric acid secretion }\end{array}$ & -1.05 \\
\hline Dll3 & Delta-like 3 & Notch signaling pathway & -1.05 \\
\hline Brca2 & Breast cancer 2 & $\begin{array}{l}\text { Homologous recombination/pathways in } \\
\text { cancer/pancreatic cancer }\end{array}$ & -1.04 \\
\hline Aqp4 & $\begin{array}{l}\text { Aquaporin } 4 \text { (Aqp4), transcript } \\
\text { variant } 2\end{array}$ & Vasopressin-regulated water reabsorption & -1.02 \\
\hline Gys2 & Glycogen synthase 2 & $\begin{array}{l}\text { Starch and sucrose metabolism/insulin signaling } \\
\text { pathway }\end{array}$ & -1.01 \\
\hline
\end{tabular}

KEGG pathway: Koto Encyclopedia of Gene and Genomes pathway. 
(b)

\begin{tabular}{|c|c|c|c|}
\hline Gene symbol & Description & KEGG pathway & $\mathrm{PIO} / \mathrm{CONT} \log 2$ ratio \\
\hline Gucy2d & Guanylate cyclase 2d (Gucy2d) & $\begin{array}{l}\text { Purine metabolism/olfactory } \\
\text { transduction/phototransduction }\end{array}$ & 1.59 \\
\hline Cyp2b1 & $\begin{array}{l}\text { Cytochrome P450, family } 2 \text {, } \\
\text { subfamily b, polypeptide } 1 \\
\text { (Cyp2b1), mRNA }\end{array}$ & $\begin{array}{l}\text { Arachidonic acid metabolism/retinol } \\
\text { metabolism/metabolism of xenobiotics by } \\
\text { cytochrome P450/drug metabolism-cytochrome } \\
\text { P450/metabolic pathways }\end{array}$ & 1.45 \\
\hline Сур $2 d 3$ & $\begin{array}{l}\text { Cytochrome P450, family } 2 \text {, } \\
\text { subfamily d, polypeptide } 3 \\
\text { (Cyp2d3) }\end{array}$ & Drug metabolism-cytochrome P450 & 1.20 \\
\hline Tarsl2 & $\begin{array}{l}\text { Threonyl-tRNA synthetase-like } 2 \\
\text { (Tarsl2), mRNA }\end{array}$ & Aminoacyl-tRNA biosynthesis & 1.17 \\
\hline $\operatorname{Prl}$ & Prolactin (Prl), mRNA & $\begin{array}{l}\text { Cytokine-cytokine receptor interaction/neuroactive } \\
\text { ligand-receptor interaction/jak-STAT signaling } \\
\text { pathway }\end{array}$ & 1.17 \\
\hline Olr1331 & $\begin{array}{l}\text { Olfactory receptor } 1331 \\
\text { (Olr1331), mRNA }\end{array}$ & Olfactory transduction & 1.17 \\
\hline Dync1h1 & $\begin{array}{l}\text { Dynein cytoplasmic } 1 \text { heavy } \\
\text { chain } 1 \text { (Dync1h1), mRNA }\end{array}$ & Phagosome/vasopressin-regulated water reabsorption & 1.11 \\
\hline Olr297 & Olfactory receptor 297 (Olr297) & Olfactory transduction & 1.06 \\
\hline
\end{tabular}

KEGG pathway: Koto Encyclopedia of Gene and Genomes pathway.

to SD rats and was decreased by PIO treatment in PCK rats (Figure 1(a)). On the other hand, the mRNA level of Ucp1 was not significantly different between PCK and SD rats (data not shown).

$S c d 1$ is involved in cell proliferation via growth factors in some type of cancer cells [16-18]. To determine the cellular distribution of Scd1 in PCK and SD kidneys, immunohistochemistry was used. In normal SD kidneys, Scd1 was hardly detected. On the other hand, in untreated PCK kidneys, Scd1 was present in the cytoplasm of normalshaped tubule epithelia diffusely but not in growing cysts. With PIO treatment, the distribution of $S c d 1$ decreased in those normal-shaped cells (Figures 1(b) and 1(c)). These findings suggest that $S c d 1$ may relate to the onset of renal cyst formation originated from normal-shaped tubules.

\section{Discussion}

In our previous report, we demonstrated that PIO treatment in PCK rats inhibited renal Raf/MEK/ERK and AKT/mTOR/S6 activity and reduced proliferation of diseased renal cells [10]. In the current study, we analyzed DNA microarray using GSEA and KEGG pathway analysis in order to detect gene-based effects of PIO treatment $[12,13]$. The results of GSEA analysis of $\mathrm{C} 5 \mathrm{BP}$ and $\mathrm{C} 2 \mathrm{CP}$ are consistent with our previous findings, as a number of gene sets related to cell cycle and cell proliferation are downregulated in kidneys of PIO-treated PCK rats.

Both EGF and PDGF pathways were downregulated by PIO treatment (Table 3(a)). In PKD cystic epithelial cells, growth factors such as EGF and PDGF activate the Raf/MEK/ERK pathway via receptor binding and tyrosine kinase activation [19-21]. Therefore, PIO may ameliorate $\mathrm{PKD}$ in PCK rats by inhibiting cell proliferation through suppression of the activity of EGF and PDGF pathways. Further, in PKD patients, several reports show that cystic kidneys have significant levels of apoptosis [22, 23]. The JNK pathway is known to have critical roles in cell apoptosis, and JNK is overexpressed in cystic epithelial cells in Pkd1 conditional knockout mice $[23,24]$. In the current study, the JNK MAPK pathway also was downregulated by PIO treatment. Therefore, PIO may have antiapoptotic effects via inactivation of the JNK pathway.

PIO, as well as other PPAR- $\gamma$ agonists rosiglitazone and troglitazone, is known to induce cell cycle arrest and cell apoptosis in human cancer cells [25-27]. Although it has recently been reported that rosiglitazone inhibits cell proliferation by inducing G1 cell cycle arrest in ADPKD cyst-lining epithelial cells [28], the inhibitory mechanism of PIO is under studied in PKD. In the current analysis, Brca2, BUB1B, Cdkn1c, Cdkn2b, Chek1, and PLK1 were downregulated. These genes are involved in cell cycle regulation, G0/G1, G1/S and/or G2/M checkpoints [29-35], suggesting that the antiproliferative effect of PIO may be related to cell cycle arrest.

After searching each gene expression with significant change by PIO treatment, we then focused on $S c d 1$ because it is known to stimulate cell proliferation in cancer cells through phosphorylation of AKT [16-18], one of the responsible kinases in cystic cell proliferation in PKD [10, 36]. Immunohistochemical analysis demonstrated that $S c d 1$ expression was increased in noncystic tubules in PCK kidneys, and PIOtreatment reduced its overexpression, suggesting that $S c d 1$ may relate to the onset of cell proliferation in initial cyst formation through phosphorylation of AKT. In addition, activation of the cell cycle increases syntheses of phospholipids and cholesterol [37-39], and Scd1 controls the balance of saturated and monounsaturated fatty acids, 


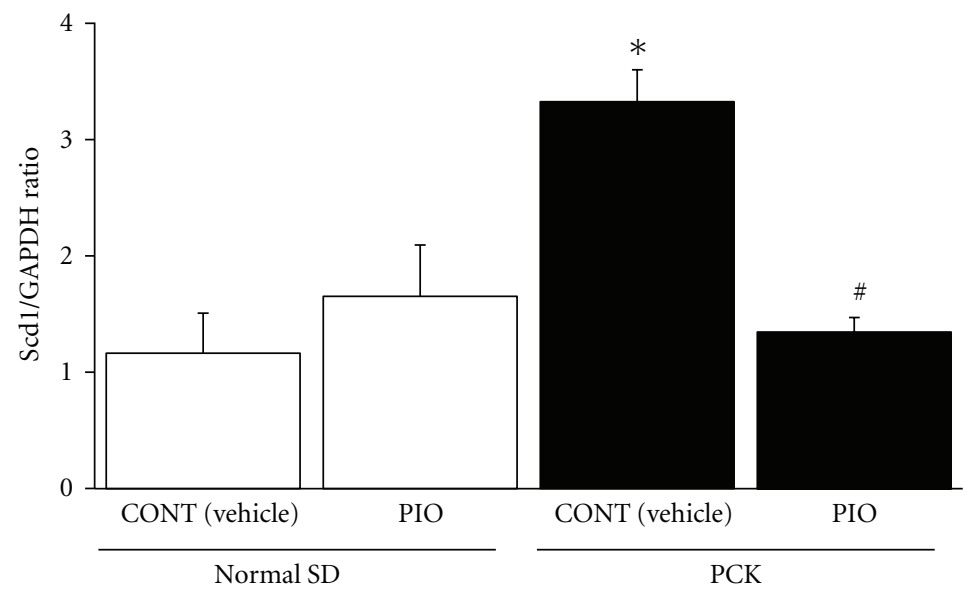

(a)
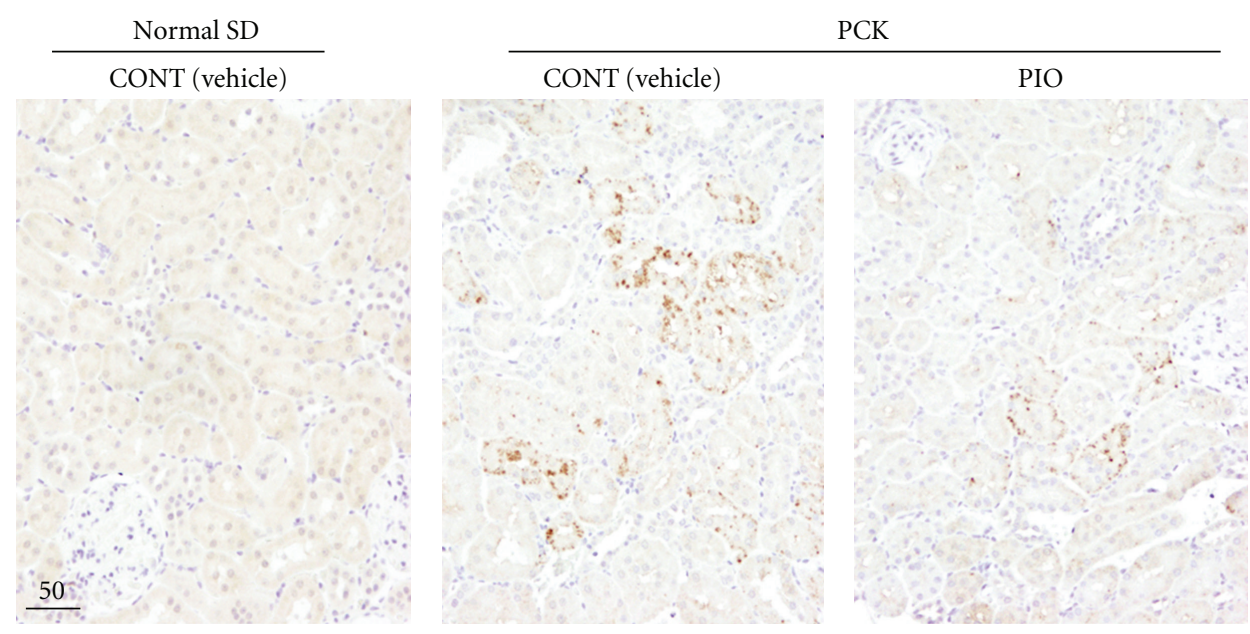

(b)

\begin{tabular}{|c|c|c|c|c|c|c|c|c|}
\hline \multirow{2}{*}{$\frac{\text { Rat strain }}{\text { Normal SD }}$} & \multirow{2}{*}{$\frac{\text { Treatment }}{\text { CONT (vehicle) }}$} & \multicolumn{3}{|c|}{ Cysts } & \multicolumn{4}{|c|}{ Noncystic tubules } \\
\hline & & & - & & 0.3 & \pm & 0.1 & \\
\hline & $\mathrm{PIO}$ & & - & & 0.3 & \pm & 0.1 & NS \\
\hline \multirow[t]{2}{*}{ PCK } & CONT (vehicle) & 0 & \pm & 0 & 10.9 & \pm & 0.3 & \\
\hline & $\mathrm{PIO}$ & 0 & \pm & 0 & 6.2 & \pm & 0.7 & $* *$ \\
\hline
\end{tabular}

(c)

Figure 1: Cellular expression and distribution of $S c d 1$ in rodent polycystic kidneys. (a) Relative gene expression levels for $S c d 1$. mRNA expression levels are shown for vehicle-treted (CONT) or PIO-treated SD and PCK kidneys as compared to vehicle-treated (CONT) SD kidneys (set to 1.0$)\left({ }^{*} P<0.05\right.$ SD (CONT) versus PCK (CONT), ${ }^{\#} P<0.05$ PCK (CONT) versus PCK (PIO)). Expression levels were normalized to GAPDH. (b) Renal Scd1 distribution in vehicle-treated (CONT) or PIO-treated SD and PCK rats. Representative kidney sections from vehicle-treated (CONT) or PIO-treated SD and PCK rats were stained with an antibody to Scd1. Mouse IgG2b, $\kappa$ isotype control antibody, did not show any reaction in the kidney. (c) Ratio of Scd1-positive cysts or noncystic tubules in kidney sections. Positivestained cysts or non-cystic tubules were counted in five random fields of kidney sections obtained from five rats in each group by a naive observer using a 20x objective. ( ${ }^{*} P<0.01$ PCK (CONT) versus PCK (PIO) in noncystic tubules in the kidney section).

regulating the composition of cholesterol esters and phospholipids in cell membrane structure [16]. Therefore, PIO may reduce cell proliferation by the downregulation of $S c d 1$ gene expression not only through reducing AKT signaling activity but also through altering fatty acid synthesis. In abnormal cell proliferation in cancer, $S c d 1$ expression is increased, and the cell proliferation is suppressed by treatment with PPAR- $\gamma$ agonists, although the changes in Scd1 expression are not always consistent [16, 40, 41]. On the other hand, in diabetes mellitus with insulin resistance, 
adipose tissue or skeletal muscle $S c d 1$ expression is decreased and increased by PPAR- $\gamma$ agonists [42-44]. Therefore, the expression level of $S c d 1$ and the effect of PPAR- $\gamma$ agonists may depend on the disease and/or the state of cell proliferation.

Clinically, increased body weight, oedema, and urinary bladder tumors are concerned as possible side effects of PPAR- $\gamma$ agonists. Although those phenomena were not observed in both genders of PCK rats in the current PIO treatment, the effect of longer term treatment with different doses will need to be studied carefully. Since ameliorative effects are reported in several animal models of PKD [8-10, 45], PPAR $-\gamma$ agonists are thought to be a potential candidate for therapeutic interventions in both ARPKD and ADPKD patients.

\section{Conclusions}

In the current study, PIO reduced PKD progression and altered the expression of renal genes involved in cell proliferation, cell cycle progression, and fatty acid metabolism in an orthologous rat model of human ARPKD. In addition to the previously demonstrated inhibition of Raf/MEK/ERK and AKT/mTOR/S6 signaling pathways by treatment of PCK rats with $10 \mathrm{mg} / \mathrm{kg}$ PIO for 16 weeks [10], suppression of cell proliferation may also be related to reductions in EGF, PDGF, and JNK pathways, cell cycle arrest related to Brca2, $B U B 1 B$, $C d k n 1 c, C d k n 2 b$, Chek1, and PLK1 genes, and alteration of fatty acid metabolism related to $S c d 1$.

\section{Acknowledgments}

This work was supported by Grant-in-Aid for scientific research (no. 22590351 to S. Nagao, and no. 23390033 to T. Abe) and 21st Century COE Program (to Fujita Health University) from the Ministry of Education, Culture, Sports, Science, and Technology of Japan and the Canadian Institutes of Health Research (MOP230564 to H. Aukema).

\section{References}

[1] J. J. Grantham, S. Mulamalla, and K. I. Swenson-Fields, "Why kidneys fail in autosomal dominant polycystic kidney disease," Nature Reviews Nephrology, vol. 7, no. 10, pp. 556-566, 2011.

[2] V. E. Torres, P. C. Harris, and Y. Pirson, "Autosomal dominant polycystic kidney disease," Lancet, vol. 369, no. 9569, pp. 12871301, 2007.

[3] P. C. Harris, "2008 Homer W. Smith award: insights into the pathogenesis of polycystic kidney disease from gene discovery," Journal of the American Society of Nephrology, vol. 20, no. 6, pp. 1188-1198, 2009.

[4] W. E. Sweeney Jr and E. D. Avner, "Diagnosis and management of childhood polycystic kidney disease," Pediatric Nephrology, vol. 26, no. 5, pp. 675-692, 2011.

[5] B. Turkbey, I. Ocak, K. Daryanani et al., "Autosomal recessive polycystic kidney disease and congenital hepatic fibrosis (ARPKD/CHF)," Pediatric Radiology, vol. 39, no. 2, pp. 100$111,2009$.

[6] A. Yessoufou and W. Wahli, "Multifaceted roles of peroxisome proliferator-activated receptors (PPARs) at the cellular and whole organism levels," Swiss Medical Weekly, vol. 140, no. 13071, pp. 4-10, 2010.

[7] C. Nofziger and B. L. Blazer-Yost, "PPAR $\gamma$ agonists, modulation of ion transporters, and fluid retention," Journal of the American Society of Nephrology, vol. 20, no. 12, pp. 2481-2483, 2009.

[8] S. Muto, A. Aiba, Y. Saito et al., "Pioglitazone improves the phenotype and molecular defects of a targeted Pkd1 mutant," Human Molecular Genetics, vol. 11, no. 15, pp. 1731-1742, 2002.

[9] B. Dai, Y. Liu, C. Mei et al., "Rosiglitazone attenuates development of polycystic kidney disease and prolongs survival in Han:SPRD rats," Clinical Science, vol. 119, no. 8, pp. 323-333, 2010.

[10] D. Yoshihara, H. Kurahashi, M. Morita et al., "PPAR- $\gamma$ agonist ameliorates kidney and liver disease in an orthologous rat model of human autosomal recessive polycystic kidney disease," American Journal of Physiology, vol. 300, no. 2, pp. F465-F474, 2011.

[11] M. Kugita, K. Nishii, M. Morita et al., "Global gene expression profiling in early-stage polycystic kidney disease in the Han:SPRD Cy rat identifies a role for RXR signaling," American Journal of Physiology, vol. 300, no. 1, pp. F177-F188, 2011.

[12] A. Subramanian, P. Tamayo, V. K. Mootha et al., "Gene set enrichment analysis: a knowledge-based approach for interpreting genome-wide expression profiles," Proceedings of the National Academy of Sciences of the United States of America, vol. 102, no. 43, pp. 15545-15550, 2005.

[13] H. Ogata, S. Goto, K. Sato, W. Fujibuchi, H. Bono, and M. Kanehisa, "KEGG: kyoto encyclopedia of genes and genomes," Nucleic Acids Research, vol. 27, no. 1, pp. 29-34, 1999.

[14] W. Arozal, K. Watanabe, P. T. Veeraveedu et al., "Telmisartan prevents the progression of renal injury in daunorubicin rats with the alteration of angiotensin II and endothelin1 receptor expression associated with its PPAR- $\gamma$ agonist actions," Toxicology, vol. 279, no. 1-3, pp. 91-99, 2011.

[15] M. Y. Chang and A. C. Ong, "Endothelin in polycystic kidney disease," Contributions to Nephrology, vol. 172, pp. 200-209, 2011.

[16] R. A. Igal, "Stearoyl-coa desaturase-1: a novel key player in the mechanisms of cell proliferation, programmed cell death and transformation to cancer," Carcinogenesis, vol. 31, no. 9, pp. 1509-1515, 2010.

[17] D. Hess, J. W. Chisholm, and R. A. Igal, "Inhibition of stearoylCoA desaturase activity blocks cell cycle progression and induces programmed cell death in lung cancer cells," PloS One, vol. 5, no. 6, p. e11394, 2010.

[18] N. Scaglia, J. W. Chisholm, and R. A. Igal, "Inhibition of stearoylCoA desaturase-1 inactivates acetyl-CoA carboxylase and impairs proliferation in cancer cells: role of AMPK," PLoS ONE, vol. 4, no. 8, Article ID e6812, 2009.

[19] T. Yamaguchi, S. Nagao, D. P. Wallace et al., "Cyclic AMP activates B-Raf and ERK in cyst epithelial cells from autosomaldominant polycystic kidneys," Kidney International, vol. 63, no. 6, pp. 1983-1994, 2003.

[20] T. Nakamura, I. Ebihara, I. Nagaoka et al., "Growth factor gene expression in kidney of murine polycystic kidney disease," Journal of the American Society of Nephrology, vol. 3, no. 7, pp. 1378-1386, 1993.

[21] S. Nagao, T. Yamaguchi, M. Kusaka et al., "Renal activation of extracellular signal-regulated kinase in rats with autosomaldominant polycystic kidney disease," Kidney International, vol. 63, no. 2, pp. 427-437, 2003. 
[22] O. Ibraghimov-Beskrovnaya, "Targeting dysregulated cell cycle and apoptosis for polycystic kidney disease therapy," Cell Cycle, vol. 6, no. 7, pp. 776-779, 2007.

[23] S. Nishio, M. Hatano, M. Nagata et al., "Pkd1 regulates immortalized proliferation of renal tubular epithelial cells through p53 induction and JNK activation," Journal of Clinical Investigation, vol. 115, no. 4, pp. 910-918, 2005.

[24] W. Yu, T. Kong, S. Beaudry et al., "Polycystin-1 protein level determines activity of the G $\alpha 12$ /JNK apoptosis pathway," Journal of Biological Chemistry, vol. 285, no. 14, pp. 10243 10251, 2010.

[25] K. Yoshizawa, D. P. Cioca, S. Kawa, E. Tanaka, and K. Kiyosawa, "Peroxisome proliferator-activated receptor $\gamma$ ligand troglitazone induces cell cycle arrest and apoptosis of hepatocellular carcinoma cell lines," Cancer, vol. 95, no. 10, pp. 2243-2251, 2002.

[26] M. Ming, J. P. Yu, X. Z. Meng, Y. H. Zhou, H. G. Yu, and H. S. Luo, "Effect of ligand troglitazone on peroxisome proliferatoractivated receptor $\gamma$ expression and cellular growth in human colon cancer cells," World Journal of Gastroenterology, vol. 12, no. 45 , pp. 7263-7270, 2006.

[27] L. Cerquetti, C. Sampaoli, D. Amendola et al., "Rosiglitazone induces autophagy in H295R and cell cycle deregulation in SW13 adrenocortical cancer cells," Experimental Cell Research, vol. 317, no. 10, pp. 1397-1410, 2011.

[28] Y. Liu, B. Dai, L. Fu, J. Jia, and C. Mei, "Rosiglitazone inhibits cell proliferation by inducing g1 cell cycle arrest and apoptosis in ADPKD cyst-lining epithelia cells," Basic and Clinical Pharmacology and Toxicology, vol. 106, no. 6, pp. 523530, 2010.

[29] E. Sagulenko, L. Savelyeva, V. Ehemann et al., "Suppression of polyploidy by the BRCA2 protein," Cancer Letters, vol. 257, no. 1, pp. 65-72, 2007.

[30] J. W. Davenport, E. R. Fernandes, L. D. Harris, G. A. M. Neale, and R. Goorha, "The mouse mitotic checkpoint gene Bublb, a novel Bub1 family member, is expressed in a cell cycledependent manner," Genomics, vol. 55, no. 1, pp. 113-117, 1999.

[31] E. Myslinski, M. A. Gérard, A. Krol, and P. Carbon, "Transcription of the human cell cycle regulated BUB1B gene requires hStaf/ZNF143," Nucleic Acids Research, vol. 35, no. 10, pp. 3453-3464, 2007.

[32] S. Sengupta, J. Nie, R. J. Wagner, C. Yang, R. Stewart, and J. A. Thomson, "MicroRNA 92b controls the G1/S checkpoint gene p57 in human embryonic stem cells," Stem Cells, vol. 27, no. 7, pp. 1524-1528, 2009.

[33] Z. Ullah, C. de Renty, and M. L. DePamphilis, "Checkpoint kinase 1 prevents cell cycle exit linked to terminal cell differentiation," Molecular and Cellular Biology, vol. 31, no. 19, pp. 4129-4143, 2011.

[34] D. T. Wu, M. Bitzer, W. Ju, P. Mundel, and E. P. Böttinger, "TGF- $\beta$ concentration specifies differential signaling profiles of growth arrest/differentiation and apoptosis in podocytes," Journal of the American Society of Nephrology, vol. 16, no. 11, pp. 3211-3221, 2005.

[35] Y. Degenhardt and T. Lampkin, "Targeting polo-like kinase in cancer therapy," Clinical Cancer Research, vol. 16, no. 2, pp. 384-389, 2010.

[36] P. R. Wahl, M. L. Hir, A. Vogetseder et al., "Mitotic activation of Akt signalling pathway in Han:SPRD rats with polycystic kidney disease," Nephrology, vol. 12, no. 4, pp. 357-363, 2007.

[37] S. Jackowski, "Cell cycle regulation of membrane phospholipid metabolism," Journal of Biological Chemistry, vol. 271, no. 34, pp. 20219-20222, 1996.
[38] M. D. Siperstein, "Role of cholesterogenesis and isoprenoid synthesis in DNA replication and cell growth," Journal of Lipid Research, vol. 25, no. 13, pp. 1462-1468, 1984.

[39] L. S. Golfman, M. Bakovic, and D. E. Vance, "Transcription of the CTP:Phosphocholine Cytidylyltransferase $\alpha$ Gene Is Enhanced during the S Phase of the Cell Cycle," Journal of Biological Chemistry, vol. 276, no. 47, pp. 43688-43692, 2001.

[40] H. Koga, K. Selvendiran, R. Sivakumar et al., "PPAR $\gamma$ potentiates anticancer effects of gemcitabine on human pancreatic cancer cells," International Journal of Oncology, vol. 40, no. 3, pp. 679-685, 2012.

[41] S. Takano, T. Kubota, H. Nishibori et al., "Pioglitazone, a ligand for peroxisome proliferator-activated receptor- $\gamma$ acts as an inhibitor of colon cancer liver metastasis," Anticancer Research, vol. 28, no. 6, pp. 3593-3599, 2008.

[42] A. Yao-Borengasser, N. Rassouli, V. Varma et al., "Stearoylcoenzyme A desaturase 1 gene expression increases after pioglitazone treatment and is associated with peroxisomal proliferator-activated receptor- $\gamma$ responsiveness," Journal of Clinical Endocrinology and Metabolism, vol. 93, no. 11, pp. 4431-4439, 2008.

[43] K. Mai, J. Andres, T. Bobbert et al., "Rosiglitazone increases fatty acid $\Delta 9$-desaturation and decreases elongase activity index in human skeletal muscle in vivo," Metabolism, vol. 61, no. 1, pp. 108-116, 2012.

[44] J. Song, H. Liu, H. W. Ressom, S. Tiwari, and C. M. Ecelbarger, "Chronic rosiglitazone therapy normalizes expression of ACE1, SCD1 and other genes in the kidney of obese zucker rats as determined by microarray analysis," Experimental and Clinical Endocrinology and Diabetes, vol. 116, no. 6, pp. 315325, 2008.

[45] B. L. Blazer-Yost, J. Haydon, T. Eggleston-Gulyas et al., "Pioglitazone attenuates cystic burden in the PCK rodent model of polycystic kidney disease," PPAR Research, vol. 2010, Article ID 274376, 8 pages, 2010. 


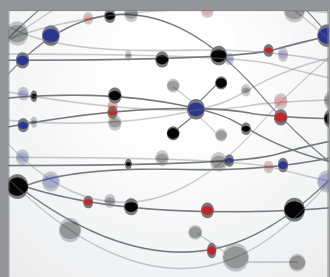

The Scientific World Journal
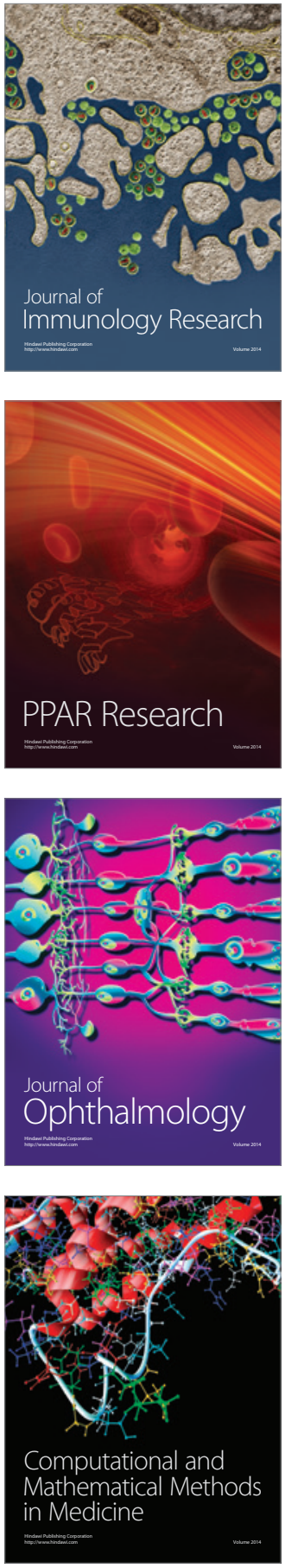

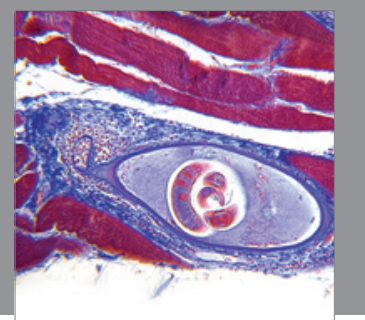

Gastroenterology

Research and Practice
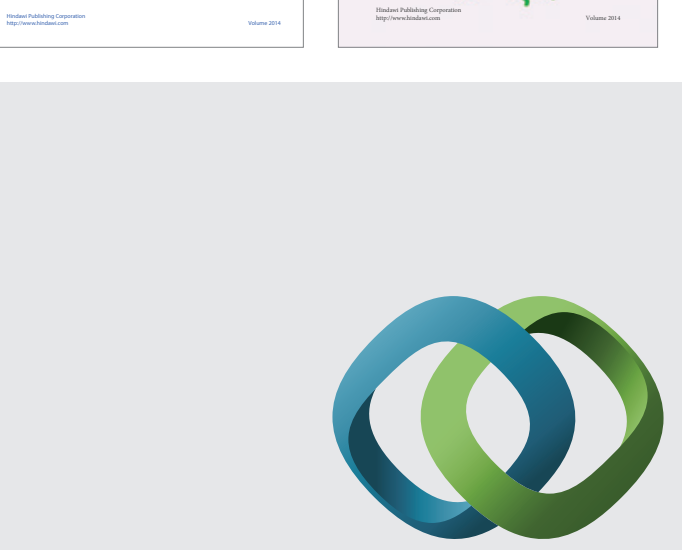

\section{Hindawi}

Submit your manuscripts at

http://www.hindawi.com
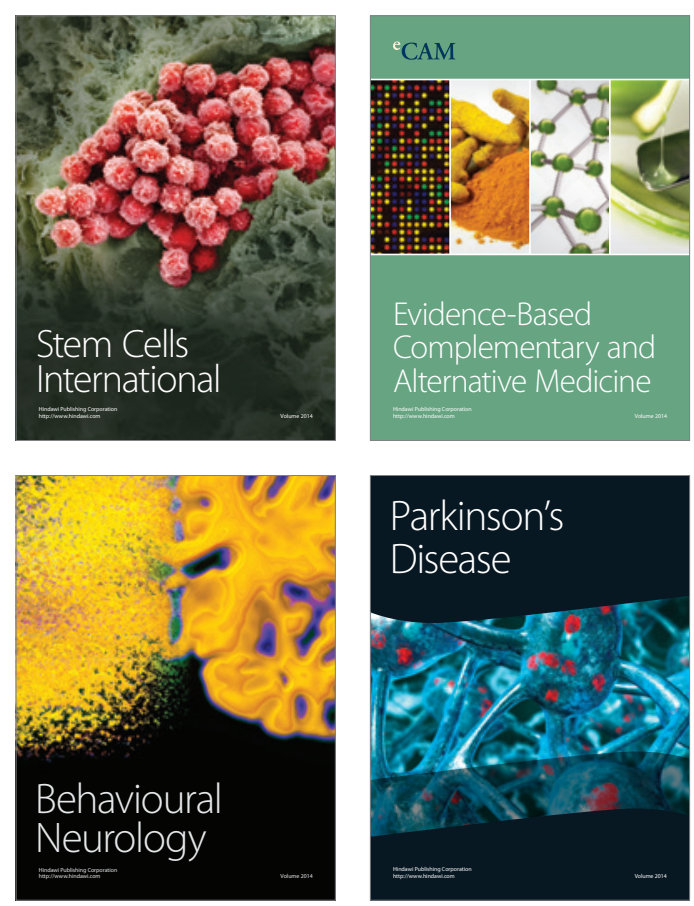

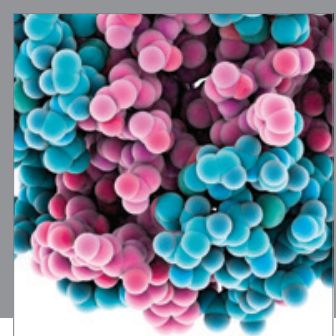

Journal of
Diabetes Research

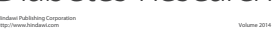

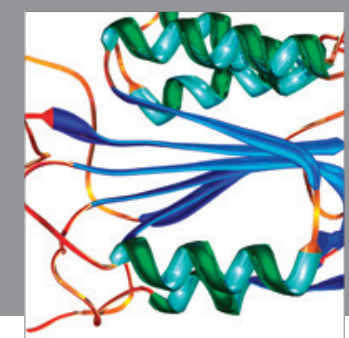

Disease Markers
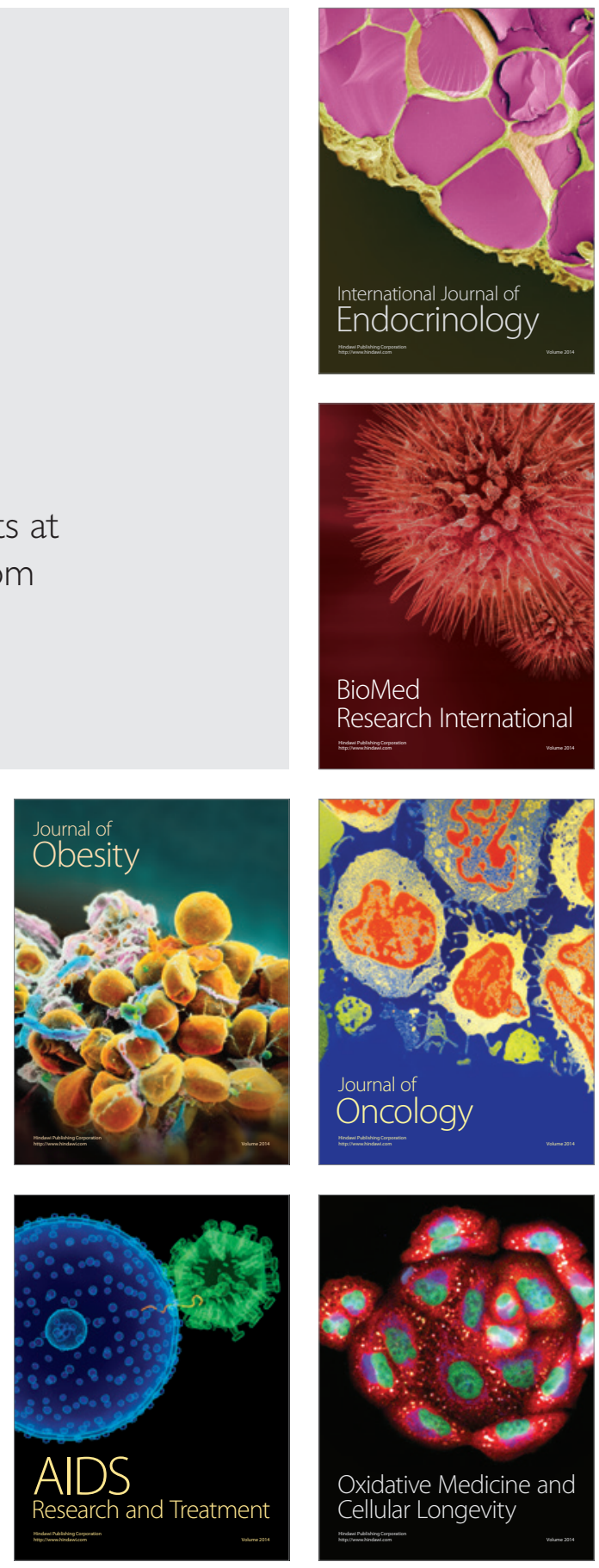